\title{
Bayesian game in customer participation open innovation research type
}

\author{
Jiahua $\mathrm{Li}^{1, \mathrm{a}}$, Junhui $\mathrm{He}^{2, \mathrm{~b},{ }^{*}}$ \\ ${ }^{1}$ Guangzhou Vocational College of Science and Technology, Guangzhou 510550, China \\ ${ }^{2}$ Department of Computer and Information Sciences, Southwest University, Chongqing 400715, \\ China
}

aemail: 908977172@qq.com, ${ }^{b^{*}}$ email:hejunhuicq@126.com, ${ }^{*}$ corresponding author

Keywords: Open innovation; Type of customers to participate; Bayesian game; incomplete information;

\begin{abstract}
Customers participating in the dynamic of the type are uncertainty. Customers to participate in open innovation process are the dynamic game of incomplete information. We have integrate dimension of customers to participate in open innovation participate to build the balance of the types of participation by the Bayesian game. Studies have shown that: separating equilibrium enterprise involved in the type of client signals to identify customers, pooling equilibrium, consumers and businesses the signal has a repeated game characteristics; semi-separating equilibrium, the client involved in acts of "path dependence". Finally, we have propose suggestions to participate in open innovation.
\end{abstract}

\section{Introduction}

One of the basic management thought of open innovation is how to face the management innovation of uncertainty. Companies face a variety of uncertainty, Thomke uncertainty (2002) to the innovation is divided into: uncertainty of innovative technology, the production, demand, and market uncertainty. In order to reduce the uncertainty, the enterprise began to adopt customer Suggestions and opinions for innovation, how to deal with customer information became the important factors of the success of open innovation [1]. Business customers to participate in the open innovation information varies, both in the customer information before new product innovation as an object type, also have customer demand, introduced in new product research and development activities, the customer involvement as a complete enterprise innovation and sustainable processes.

Apple, Procter \& gamble and other famous enterprises open innovation practice shows that customers to participate in the open innovation has become a hot field of industry innovation practice. But customer involvement in the process of facing the customer number, demand dynamic change, the information uncertainty characteristics [2], the enterprises face customer involvement type of dynamic and uncertainty, make the enterprise to accept customer open innovation with incomplete information and dynamic change characteristics (Frank Piller, 2011) [3]. Which dimensions affect the customer participate in the open innovation, enterprise mechanism by which the customer into the participation of open innovation, few theoretical research at present. This study attempts to integrate customer involvement dimension of open innovation, put forward the customer participate in the open innovation type, with incomplete information dynamic game perspective construct Bayesian signal game model, through balancing and discussion, thus draws the enterprise identify types of customers to participate in the open innovation mechanism, in order to provide references for open innovation activities.

\section{Customer involvement type of open innovation}

According to the customer participate in the literature research of enterprise innovation, we believe that the customer can promote enterprise under different modes and intensity of new product innovation activities [2]. And customers to participate in the open innovation practice tells 
us: the customer with the open innovation of the enterprise, is a diversified phenomenon, need from the customer and enterprise dimensions in the interaction process of characteristics. Based on the previous research achievements of open innovation, Diener and Piller (2010), the characteristics of open innovation [9], we integrated the three customers to participate in the characteristics of open innovation:

Customer involvement of open innovation stages: the customer into the timing of the open innovation [2]. This feature is mainly depict the customer in the enterprise which stage of the new product innovation, appropriate into open innovation. Exist in practice, such as new product concept design, research and development in the early period of the design phase, or a new product, new product trial test, etc. In the late stage. We define it participate in open innovation for the customer the front-end and back-end two dimensions.

Customers participate in the open innovation synergy degree: refers to the basic relationship in an open innovation structure, the innovation of the enterprise how to deal with the customer set, namely a synergistic innovation enterprises exist at the same time mathematical how many customers, and the close degree [9]. We define it as the customer participate in the open innovation synergy degree high and low two dimensions.

Customers participate in the open innovation degree of freedom: refers to the open innovation enterprise mission, assigned to the nature of the customer, give customer free innovation space [9]. Namely enterprise task of open innovation is a narrow and scheduled tasks, or is a relatively free of loose, creative task. We define it participate in open innovation for the customer the freedom degree is high and the low degree of freedom in two dimensions.

\section{Customer participation in open innovation type of bayesian game}

Customers to participate in the open innovation type explains the relationship between customers and enterprises in the open innovation activities, but more is the enterprise Angle signal, especially in the perspective of enterprise established signal to release. With the development of practice, in the process of customers to participate in the obvious signal receiving and signal feedback, and enterprise simple signal launch effective integration. Enterprises in the innovation process front end customers to participate in the signal, the filtered signal feedback of customers to participate in the open innovation into new product innovation, the innovation process at the same time the back-end according to the characters of customers personalized needs of matching. Considering the mass customers cause differences between innovation synergy degree and the degree of freedom, many enterprises through the network community building customer participation signal interaction mechanism, is considered to be effective individual customer "sticky" [14], at the same time take into account customer open innovation brought by the division of signal integration costs, thereby better produce knowledge sharing [15].

Visible customers to participate in the open innovation type presents obvious uncertainty and dynamics. Enterprise in open innovation activities in trying to understand customers to participate in the open innovation type, need from their own and in the "signal" from the customer identification information, customer involvement types and characteristics, but customers are numerous, participate in various ways, and the customer and the enterprise does not exist in the signal propagation "common knowledge", customer had cost between innovation integration, customer itself also unconscious information summarized on innovation activities, these features constitute the customer participate in the open innovation main body "there is no complete information" (incomplete information). Due to incomplete information, we consider using Bayesian game signal game model to study the equilibrium paths.

Main assumptions in the open innovation, game (use) for the enterprise and customer (said). For companies, customers can be set through the open innovation and opening process involved in the front-end and back-end open innovation, there are two categories in types for clients, collaborative involvement (that is, the high degree of synergy) with said $C O$, free participation (i.e., high degree of freedom) use, said $F R$, these two kinds of types and stages of participation can be combined for 
multiple participation way $T=\{C O, F R\}$. Customers and the enterprise does not exist "common knowledge" [16] : customers can predict their participation way and don't know, enterprise can't be calculated directly by observing the client participation way, only by some signal from the customer to determine the client type. Assuming enterprise determine customers belong to the prior probability of role for, belong to participate in the prior probability of freedom, customers participate in open innovation cost, customers can through participating in phase with ease to the signal from the relevant type of enterprises, assumed $\mu(C O)=1-q$, and optimal return is to give customers a corresponding expected return $\mu(F R)=q$.

In the practice of open innovation, open innovation ability to match to consumers and businesses each have differences, common view is the stronger the open innovation matching to consumers and businesses, the synergy degree is higher, the opposite is more suitable for customers free innovation [9], participation with our customers so we assume that the ability of cost less than only to participate in, namely $c_{e}(F D, e)>c_{e}(C O, e) . c_{e}(t, e)$ is type matching, a level for the customer to participate in the marginal cost of open innovation.

Customers to participate in the open innovation to provide the utility level of expectations

$u_{\mu}(e)=\mu(C O \mid e) \times y(C O, e)+\mu(F D \mid e) \times y(F D, e)$

To match capacity for customers choose utility maximization according to the following rules:

$$
\begin{aligned}
& \max _{e} U_{S}(t)=y(t, e)-c(t, e) \\
& \text { If: } e^{\wedge}(t)=\arg \max _{m}[y(t, e)-c(t, e)] \\
& \text { And } e^{\wedge}(C O, F D)=\arg \max _{m}[y(F D, e)-c(C O, e)]
\end{aligned}
$$

\section{A dynamic game model of Bayesian equilibrium analysis}

According to the model, we attempt to find a Bayesian game model equilibrium path. We will analyze the model, and with various forms of equilibrium results is given.

(1) separating equilibrium

Separating equilibrium said of the different types of participants can choose different types of action. In customers to participate in the activities of open innovation, separating equilibrium said of the different types of customers have a different ability to match signals, enterprise can according to customer's signal type to determine customer belongs to type. Type for customer's utility will be at a point on the line $u_{F D}=y(F D, e)$. Because of the type of customer representative is matching ability is relatively lower, so he will choose $e^{\wedge}(F D)$ to own utility maximization, and the signal $u_{F D}=y(F D, e)$ is actually. That is, the type of customer is will curve and the line tangent to point, and he gained by the utility for. Therefore, under the separating equilibrium, as a type of customer, $e^{*}(F D)=e^{\wedge}(F D)$ and $\underline{U}(F D)=U^{*}(F D)$.

We can conclude that $e_{a} \leq e^{*}(C O) \leq e_{b}, e^{*}(F D)=e^{\wedge}(F D), \quad e^{*}(C O)=e^{\wedge}(C O)$,

$$
\mu^{*}\left(F D \mid e^{*}(F D)\right)=1, \quad \mu^{*}(C O) \mid e^{*}(C O)=1, \quad \mu^{*}(F D \mid e)=1 \text {. }
$$

(2) With balanced

With balanced said different customers to send the same signal, extreme send signals are the same for all customers, order $e^{*}(C O)=e^{*}(F D)=e^{*}$, the recipient enterprise cannot be observed directly from the signal information customer participation behavior, enterprise will not modify prior probability, thus there are $\mu(F D)=q$. Because the utility of the customer is enterprise's expectations of his open innovation, in the condition of equilibrium, the utility of the two customers in the line

$$
\mathrm{u}_{\mu}=\mu(C O) \times y(C O)+\mu(F D) \times y(F D)
$$


A balanced conclusion is that the enterprise can through the repeated game with customers for the best, thus the customer type dynamic.

(3) Separation equilibrium

Accurate separation equilibrium assumes a signal issued only one type of participants, another signal can be chosen by more than one type. Followed by probabilistic is $\mu \mathrm{e}^{* *}=\frac{P c o}{p c o+p F D q}: e \neq e^{* *}$ and $\mu \mathrm{e}=0$.

According to the Bayesian equilibrium $u_{\mu}\left(e^{* *}\right)=\mu\left(e^{* *}\right) \theta^{C O}+\left(1-\mu\left(e^{* *}\right)\right) \theta^{F D}$, can get the optimal utility level expectations, among them $\theta^{F D}=\left(\mu\left(e^{* *}\right) \theta^{C O}+\left(1-\mu\left(e^{* *}\right) \theta^{F D}\right)-c\left(e^{* *}\right)\right.$, the adjustment that customer's behavior without apparent effectiveness improvement.

Visible, must separate equilibrium under the customer although the initial choice is different, but once how enterprise form collaborative innovation relations with customers and coordination the customer will not take part in the ( $\mathrm{CO}$ ) from motivation, innovation and free customer no motivation preferences become customer collaborative innovation, must separate balanced conclusion is: the customer to participate in the activities of open innovation has a certain degree of "path dependence".

\section{Conclusion}

First of all, the enterprise can optimize customer involvement in the innovative activities of open innovation governance mechanism, effective to identify the customer type. Separating equilibrium conclusion has been proved that if the enterprise known as steps in the research and development activities, through the clear rules and clear process of participation and reward plan and solve the conflict between customer mechanism, a clear signal that has the prior probability, to the customer for customer actively choose to participate in type, and then sends a signal. Such as taobao (try.taobao.com) customers free access to trial samples, muji (muji.com.cn) online community (Muji.net), information integration and so on all is by optimizing the customer participate in the governance mechanism, realize the customer type identification.

Second, enterprises in the innovation activities can be distributed innovation mode, dynamic identification of customer type. With equilibrium analysis tells us that the innovation of the enterprise activity scale, process complex, need customers to participate in the number of cases, companies need to interact with customers to form many times in the innovative activities, to help customers choose to participate in the timing and to participate in the project. Such as Boeing aircraft community (www.newairplane.com), through the network to recruit more than 120000 people around the world as a Boeing volunteers, volunteers in accordance with the company's project, modular decomposition in aircraft concept formation, appearance design, component design, and production areas such as modular matching according to the customer's motivation and ability.

The other is open innovation through customer relationship management (CRM) information integration, help enterprise to identify types of customers to participate in the open innovation. For most of the industry enterprises, the number of customers is more huge, even now many industries are using statistical method to predict customer needs, while differentiation and dynamic customer demand, but must separate equilibrium, customer participation behavior is "path dependence", so to find a new customer coordination degree is high, as soon as possible, make its produce "participation depends on innovation" is the enterprise effective classification important path of the clients. Under the background of normalization, can consider through customer relationship management (CRM), such as, decision support system and so on specific methods of mass customization customers scattered information integration, and combining its own resources and customer information effectively, and ultimately determine the identification of customer types, open innovation for decision support to the company. 


\section{Acknowledgement}

In this paper, the research was sponsored by the Fundamental Research Funds for the Central Universities (XDJK2013C012)

\section{References}

[1]Thomke, S., \& von Hippel, E. (2002). Customers as innovators: a new way to create value. Harvard Business Review,80(4), 74 - 81.

[2]Dahan, E., \& Hauser, J. R. (2002). The virtual customer. Journal of Product Innovation Management, 19(5), 332 - 353

[3]Frank Piller, (2011). From Social Media to Social Product Development:The Impact of Social Media on Co - Creation of Innovation. Working Paper. Electronic copy available at: http://ssrn.com/abstract=1975523

[4]Füller, J., Jawecki, G., \& Mühlbacher, H. (2006). Innovation creation by online basketball communities. Journal of Business Research, 60(1), 60 - 71.

[5]Bullinger, A.C. et al. (2010): Community - Based Innovation Contests: Where Competition MeetsCooperation, in: Creativity and Innovation Management, Vol. 19, No. 3, S. 290-303.

[6]von Hippel, E., \& Katz, R. (2002). Shifting innovation to users via toolkits. Management Science, 48(7), 821 - 833.

[7]Boudreau, K. J. et al. (2011): Incentives and Problem Uncertainty in Innovation Contests: An Empirical Analysis, in: Management Science, Vol. 57, No. 5, S. 843 - 863

[8]Culnan, M. J. et al. (2010): How large U.S. companies can use twitter and other social media to gain business value, in: MIS Quarterly Executive, Vol. 9, No. 4, S. 243 - 259.

[9]Diener, K. and Piller, F. (2010). The Market for Open Innovation. Raleigh, NC: Lulu 2010.11-13

[10]O’Hern, M.S., \& Rindfleisch, A. (2009). Customer co - creation: a typology and research agenda. In Review of Marketing Research, Volume 6. ed. Naresh K. Malhotra, Armonk, NY: Sharpe, 84 - 106.

[11]Füller, J., Jawecki, G., \& Mühlbacher, H. (2006). Innovation creation by online basketball communities. Journal of Business Research, 60(1), 60 - 71.

[12]Franke, N. et al. (2010): The “I Designed It Myself” Effect in Mass Customization, in: Management Science, Vol. 56, No. 1, S. 125-140.

[13]Frank Piller*, Christoph Ihl and Alexander Vossen (2010). Aachen A typology of customer co - creation in the innovation process:23-25

[14]Fuchs, C./Schreier, M. (2011): Customer Empowerment in New Product Development, in: Journal of Product Innovation Management, Vol. 28, No. 1, S. 17-32.

[15]Hutter, K. et al. (2011): Communitition: The tension between competition and collaboration in community - based design contests, in: Creativity and Innovation Management, Vol. 20, No. 1, S. 3 $-21$ 